\title{
EL USO DEL IMPERFECTO DE SUBJUNTIVO EN EL HABLA CULTA DE COSTA RICA
}

\author{
PeTR PITLOUN \\ Universidad Noruega de Ciencias Económicas \\ y Empresariales
}

\section{INTRODUCCIÓN}

Este trabajo se propone describir los usos del imperfecto de subjuntivo en el habla culta de Costa Rica. Además, trata de averiguar la distribución de las formas cantara y cantase en esta variante del español moderno.

Para ello se usa el material recogido por Yamilet Solano según las pautas establecidas para el Proyecto de estudio coordinado de la norma lingüística culta de las principales ciudades de Iberoamérica y de la Península Ibérica, cuyo iniciador fue, en 1964, Juan Manuel Lope Blanch. El propósito de este proyecto ha sido

el análisis y descripción de las realidades idiomáticas específicas que caracterizan a cada uno de los países que tienen el español como lengua oficial: se podría llegar así al conocimiento de la norma hispánica común, es decir al conocimiento de la 'unidad dentro de la diversidad', de la 'unidad variada' o 'variedad uniforme' 1

El material de Solano está constituido por 34 entrevistas, que corresponden a casi 18 horas de grabación. Los informantes fueron seleccionados atendiendo a varios factores socioculturales: a) todos son del área metropolitana de San José o son residentes en esta zona desde los cinco años de edad; b) todos tienen educación superior; c) todos hicieron su enseñanza primaria, secundaria y universitaria en la misma ciudad; d) todos son hijos de hispanohablantes. Las entrevistas incluyen diferentes situaciones comunicativas: entrevistas informales y formales entre el informante y la entrevistadora, diálogos entre dos informan-

\footnotetext{
${ }^{1}$ Rosalba Iuliano, «La perífrasis ir + a + (infinitivo) en el habla culta de Caracas», 1975 Colloquium on Hispanic Linguistics, Frances M. Aid, Melvyn C. Resnick y Bohdan Saciuk, eds., Washington, Georgetown University Press, 1975, págs. 59-66.
} 
tes y conferencias. Los temas son libres y tienen relación con la vida y la profesión de los informantes. Nunca se consideró el habla de la entrevistadora como material de análisis.

Sobre la base de este material ya se han hecho varias investigaciones que describen diferentes aspectos del sistema verbal del habla culta costarricense. Entre estos estudios está el de Montero Blanco y Rojas Sánchez, quienes escribieron un trabajo sobre el uso de las formas verbales de futuro en el que establecen la frecuencia de uso de estas formas e indican las formas que las sustituyen $^{2}$. Murillo, a su vez, trató el tema del presente de subjuntivo y de la variación modal ${ }^{3}$, mientras que Pitloun describió las frecuencias y los usos de los tiempos verbales del modo indicativo ${ }^{4}$. Otro trabajo de Pitloun está dedicado a la perífrasis ir $a+$ infinitivo y a la expresión de la posterioridad ${ }^{5}$.

\section{IMPERFECTO DE SUBJUNTIVO: CONSIDERACIONES GENERALES}

En el imperfecto de subjuntivo español se fundieron dos formas latinas: el pluscuamperfecto de indicativo y el pluscuamperfecto de subjuntivo.

La forma latina del imperfecto de subjuntivo CANTĀREM fue sustituida ya en latín vulgar por el pluscuamperfecto de subjuntivo CANTĀVISSEM, que pasó al imperfecto de subjuntivo y se transformó en cantase (CANTĀVISSEM > CANTĀSSEM > cantas $($ se $)>$ cantase). Parece que esta sustitución empezó a darse primero en las oraciones condicionales que expresan hechos hipotéticos en el presente o en el futuro Sİ POTUISSET, ID FĒCISSET ('Si pudiese / pudiera, lo haría'), que se usaba anteriormente solamente para expresar hechos hipotéticos en el pasado ('Si hubiese / hubiera podido, lo habría hecho'). La original lejanía temporal de CANTĀVISSEM podría haber enfatizado en este tipo de oraciones la improbabilidad de que se cumpliera la condición. De allí fue cantase extendiendo sus funciones, y hasta finales de la Edad Media fue la única forma con valor del imperfecto de subjuntivo ${ }^{6}$.

La forma del imperfecto de subjuntivo en ra proviene de la forma latina del pluscuamperfecto de indicativo CANTĀVERAM (CANTĀVERAM > CANTĀRAM

${ }^{2}$ Luz Mary Montero Blanco y Xeyna Rojas Sánchez, El uso de las formas verbales de futuro en el habla culta costarricense, Tesis de licenciatura inédita, Universidad de Costa Rica, Sede de Occidente, 1993.

${ }^{3}$ Jorge E. Murillo, El presente de subjuntivo y la variación modal en el habla culta costarricense, Tesis doctoral inédita, State University of New York at Albany, 1998.

${ }^{4}$ Petr Pitloun, Los tiempos verbales de indicativo en el habla culta costarricense, Tesis doctoral, Bergen, Universidad de Bergen, 2003.

${ }^{5}$ Petr Pitloun, «La perífrasis ir a + infinitivo y la expresión de la posterioridad en el habla culta de Costa Rica», Revista de Filología y Lingüística, Universidad de Costa Rica, 31/1, 2005.

${ }^{6}$ Ralph Penny, A History of the Spanish Language, Cambridge, Cambridge University Press, 2004, págs. 201-203. 
> cantara). Cantara, sin embargo, mantuvo todavía en español antiguo su significado latino de pluscuamperfecto de indicativo y se usaba a la par del pluscuamperfecto perifrástico haber + participio, hasta que fue casi completamente desplazada por éste a principios del Siglo de Oro. Ya en latín tardío, no obstante, CANTĀVERAM adquirió el valor del condicional después de que se comenzó a emplear en la apódosis de los períodos condicionales SĪ POTUISSET, ID FĒCERAT ('Si pudiese / pudiera, lo haría', o también, en aquel entonces, 'Si hubiese / hubiera podido, lo habría hecho'). Con este valor del condicional y condicional perfecto aparece cantara bastante frecuentemente en el español antiguo y todavía en el español del Siglo de Oro. A finales de la Edad Media pasó cantara de la apódosis a la prótasis, haciéndose equivalente de cantase y adoptando así el valor del imperfecto de subjuntivo, aunque tan solo en las oraciones condicionales. El uso de cantara en otros tipos de oraciones como forma alternativa de cantase no se consolidó sino hasta el siglo XIX ${ }^{7}$.

Parece que la frecuencia del uso subjuntivo de cantara se equilibra con la del indicativo en el siglo XIV. En el siglo XV comienza el predominio del empleo subjuntivo. Su uso con valor del pluscuamperfecto de indicativo va haciéndose menos frecuente, hasta que cae prácticamente en desuso en la segunda mitad del siglo XVII. Sin embargo, los escritores de fines del siglo XVIII y los románticos, por imitación de los textos antiguos y especialmente del Romancero, restauraron este uso de cantara, que persiste más o menos hasta nuestros días:

(1) Recordó entonces el sobre azul que dejara al acostarse sobre la desvencijada mesilla ${ }^{8}$.

A veces se encuentra la forma cantara no ya como equivalente a había cantado, sino como a un pretérito perfecto simple:

(2) Se comenta el discurso que anoche pronunciara el Presidente?

En el habla coloquial de algunos países de América se conserva el uso de la forma en $r a$ en la apódosis de las oraciones condicionales, donde sustituye al condicional: Si pudiese / pudiera, lo hiciera. Por otro lado, está extendido, tanto en la lengua hablada como en la literaria, su uso con valor del condicional en los verbos modales poder, deber y querer ${ }^{10}$.

\footnotetext{
${ }^{7}$ Ralph Penny, op. cit., págs. 204-205.

${ }^{8}$ Miguel Delibes, Aún es de día, 10, Gramática de la lengua española, Emilio Alarcos Llorach, Madrid, Espasa Calpe, 1999, § 223.

${ }^{9}$ Real Academia Española, Esbozo de una nueva gramática de la lengua española, Madrid, Espasa, 1973, pág. 480.

${ }^{10}$ Samuel Gili Gaya, Curso superior de sintaxis española, Barcelona, Bibliograf, 1970, §§ 135-136. Real Academia Española, op. cit., págs. 480-481.
} 
El empleo literario de la forma cantara con valor de los tiempos pasados de indicativo ha permanecido, pues, vivo hasta nuestros días, a pesar de que los gramáticos, por lo general, condenan esta manera de usarla. Bello, por ejemplo, lo considera como arcaísmo que debe evitarse porque puede producir confusión ${ }^{11}$. Cantara, desde su punto de vista, tiene ya en el español moderno demasiados significados para que se le agregue otro más. «Lo peor es el abuso que se hace de este arcaísmo, empleando la forma cantara, no sólo en el sentido de había cantado, sino en el de canté, cantaba y he cantado», concluye. La crítica más dura contra el uso de cantara con este valor la encontramos probablemente en Mallo. En su opinión,

de todos los atentados que (...) se cometen contra la unidad, la pureza y la corrección de la lengua española, ninguno es (...) tan grave y peligroso como el que consiste en emplear las formas verbales del pretérito imperfecto de subjuntivo terminadas en «ra» (...) en función de algunos tiempos pasados del indicativo ${ }^{12}$.

Y más adelante añade que «se trata de un fenómeno lingüístico no biológico y espontáneo, sino producto de la afectación, de la petulancia y del desconocimiento de la gramática» que los mejores autores evitan. Para Alarcos Llorach el empleo de cantara por canté es «afectado, periodístico y dialectal» ${ }^{13}$. $\mathrm{Su}$ uso por había cantado lo tilda de «arcaísmo o dialectalismo». La RAE, a su vez, solamente constata que el uso de cantara «no ya como pluscuamperfecto, sino como un pretérito cualquiera de indicativo» no está justificado «en modo alguno por la tradición del idioma» ${ }^{14}$. Wright, por el contrario, defiende este uso de cantara y lo concibe como resultado del desarrollo natural de la lengua, que siempre está en búsqueda de nuevos modos de dar énfasis y vivacidad a ciertas ideas. El autor, al mismo tiempo, presenta una lista en la que enumera 30 acepciones de la forma en $\mathrm{ra}$. El hecho de que cantara sea capaz de desempeñar tantas funciones le permite concluir que se trata de la forma verbal más útil del sistema verbal español ${ }^{15}$. En respuesta a este trabajo de Wright, Mallo subraya que desde el Siglo de Oro la frecuencia del uso de cantara con valor de los tiempos pasados de indicativo ha sido siempre insignificante, tanto en los escritores españoles como en los hispanoamericanos, y que nunca ha tenido «el carácter de tendencias populares ni colectivas» ${ }^{16}$.

${ }^{11}$ Andrés Bello, Gramática de la lengua castellana, 1847, Obras completas de Andrés Bello, Caracas, Ministerio de Educación, t. IV, 1951, § 720.

12 Jerónimo Mallo, «El empleo de las formas del subjuntivo terminadas en «ra» con significación de tiempos del indicativo», Hispania, 30, 1947, págs. 484-487.

${ }^{13}$ Emilio Alarcos Llorach, op. cit., § 223.

${ }^{14}$ Real Academia Española, op. cit., pág. 480.

${ }^{15}$ Leavitt O. Wright, «The Spanish Verb-Form with the Greatest Variety of Functions», Hispania, 30, 1947, págs. 488-495.

${ }^{16}$ Jerónimo Mallo, «La discusión sobre el empleo de las formas verbales en «ra» con función de tiempos pasados de indicativo», Hispania, 33, 1950, págs. 126-139. Según Kany, por otra 
El significado temporal de las formas del imperfecto de subjuntivo puede ser presente, pasado o futuro, si tomamos como punto de referencia el momento en que hablamos. Cantara y cantase corresponden a tres tiempos verbales del indicativo: pretérito perfecto simple (canté), pretérito imperfecto (cantaba) y condicional (cantaría) ${ }^{17}$ :

(3a) Creo que llegó temprano.

(3b) No creo que llegara / llegase temprano.

(4a) Creo que quería llegar temprano.

(4b) No creo que quisiera / quisiese llegar temprano.

(5a) Creo que llegaría temprano.

(5b) No creo que llegara / llegase temprano.

Porto Dapena y Sastre Ruano precisan que el imperfecto de subjuntivo puede expresar un hecho anterior al momento en que se habla, como en (6); un hecho simultáneo o posterior al momento del habla, como en (7) y (8), respectivamente; un hecho simultáneo a un punto anterior al del habla, como en (9); $\mathrm{y}$ un hecho posterior a un punto anterior al momento en que se habla. Este punto, a su vez, puede ser anterior, simultáneo o posterior al momento del habla, como en $(10)^{18}$ :

(6) Quizás lo hiciera / hiciese ayer.

(7) Ojalá estuviera / estuviese ahora aquí con nosotros.

(8) Me gustaría que la próxima vez viajaras / viajases conmigo.

(9) Quería que siguiéramos / siguiésemos bailando.

(10) Me pidieron que les contara / contase sobre mi infancia ${ }^{19}$.

parte, el uso de la forma en ra con valor de los tiempos pasados de indicativo se limita en España principalmente a las oraciones relativas y adverbiales, siendo más frecuente en los hablantes y escritores del norte del país (Galicia y Asturias). En Hispanoamérica, en cambio, este uso de cantara se registra en la mayoría de los escritores, incluyendo a los mejores. Kany, además, aclara que los escritores hispanoamericanos utilizaban esta forma como medio estilístico con el fin de darles un matiz histórico a sus obras. En la actualidad, sin embargo, este uso se ha generalizado tanto en la mayoría de los autores que ha perdido su original rasgo arcaizante. Podemos encontrarlo con mayor frecuencia en las oraciones relativas, a menudo en las adverbiales, y ocasionalmente en las principales. No se registra en la lengua corriente. (Charles Kany, Sintaxis hispanoamericana, Madrid, Gredos, 1969, págs. 209-211.) También Nowikow, después de revisar el empleo de la forma en $r a$ en periódicos y revistas de diferentes países hispanohablantes, llega a la conclusión de que «en el castellano moderno cantara dejó de ser un arcaísmo estilístico, convirtiéndose en una forma más bien neutral, aunque su empleo se limita a los estilos funcionales de la literatura, la prensa (o la radio) y los discursos». (Wiàczesław Nowikow, «El aspecto estilístico del empleo indicativo de la forma en ra», Folia Lingüistica, 14, 1986, págs. 167-176).

${ }^{17}$ Real Academia Española, op. cit., pág. 479.

${ }^{18}$ José Álvaro Porto Dapena, Tiempos y formas no personales del verbo, Madrid, Arco/Libros, 1989, págs. 127-129. María Ángeles Sastre Ruano, El subjuntivo en español, Salamanca, Ediciones Colegio de España, 1997, págs. 26-27.

${ }^{19}$ En (10), "me pidieron que les contara sobre mi infancia" puede significar "me pidieron que les contara ayer', 'me pidieron que les contara ahora' o 'me pidieron que les contara mañana'. 
Aunque pertenecen al mismo tiempo verbal, cantara y cantase no siempre pueden usarse indistintamente. Se pueden sustituir entre sí siempre que sean subjuntivas ${ }^{20}$. Alarcos Llorach comparte este punto de vista: «Aunque en su origen latino diverso designaban valores diferentes, la lengua moderna ha terminado por identificarlas, de manera que hoy se trata de dos significantes que abarcan un mismo significado» ${ }^{21}$. Lenz se muestra aún más categórico al respecto: «(...) si cantara se usa como subjuntivo, es absoluto sinónimo de cantase, una mera variante formal» ${ }^{22}$. No obstante, encontramos también autores que ponen en duda la libre alternancia de las dos formas del imperfecto de subjuntivo. Bolinger (1956: 346), por ejemplo, opina que la forma en se implica «remoteness, detachment, hypothesis, lack of interest, vagueness, greater unlikelihood, while - $r a$ brings everything into relatively sharper focus» ${ }^{23}$.

En cuanto al predominio de una u otra forma, depende de estilos y preferencias individuales o colectivas. En la lengua corriente predomina generalmente la forma en se, mientras que en la lengua culta y literaria, la forma en $\mathrm{ra}^{24}$. Alarcos Llorach más tarde corrige la afirmación de la RAE sosteniendo que cantara es «de uso más frecuente en la expresión oral», mientras que cantase es «más propio de la escrita, sobre todo como recurso de variación estilística» ${ }^{25}$. Kany, por su parte, afirma que cantase «casi ha desaparecido del habla de la mayor parte de Hispanoamérica» ${ }^{26}$. Moreno de Alba confirma el predominio de cantara en esta región: «En América se prefiere casi siempre y en prácticamente todos los dialectos y registros la forma en -ra sobre la forma en $-s e{ }^{27}$. Refiriéndose al español de Chile, Lenz señala que el pueblo utiliza exclusivamente la forma en $r a$. Algunos autores, sin embargo, usan con frecuencia la forma en se «porque, siendo más rara, creen que es más elegante» ${ }^{28}$.

${ }^{20}$ Real Academia Española, op. cit., pág. 481.

${ }^{21}$ Emilio Alarcos Llorach, op. cit., § 223.

${ }^{22}$ Rodolfo Lenz, La oración y sus partes, Madrid, Centro de Estudios Históricos, 1925, § 306.

${ }^{23}$ Dwight L. Bolinger, «Subjunctive $-r a$ and $-s e$ : «Free Variation»?», Hispania, 39, 1956, págs. 345-349.

${ }^{24}$ Real Academia Española, op. cit., pág. 481.

${ }^{25}$ Emilio Alarcos Llorach, op. cit., § 223.

${ }^{26}$ Charles Kany, op.cit., pág. 222.

${ }^{27}$ José G. Moreno de Alba, El español en América. México, D. F., Fondo de Cultura Económica, 1995, pág. 187.

${ }^{28}$ Rodolfo Lenz, op. cit., $§ 289$. DeMello, a su vez, estudió las frecuencias del uso de cantara y cantase en el habla culta de Bogotá, Buenos Aires, Caracas, La Habana, Lima, Madrid, Ciudad de México, San Juan (Puerto Rico), Santiago de Chile y Sevilla, y llegó a las siguientes conclusiones: 1. la forma en $r a$ se usa con mucha más frecuencia que la forma en $s e$, tanto en España como en Hispanoamérica; 2. la forma en se no ha desaparecido por completo del español americano; 3. el uso de cantase es más elevado en San Juan (20\%), en Madrid (16\%) y en Sevilla $(13 \%)$. En las demás ciudades su incidencia oscila entre un $0,6 \%$ (Lima) y un $6 \%$ (Buenos Aires y Caracas). (George DeMello, «-Ra vs. -Se Subjunctive: A New Look at an Old Topic», Hispania, 76, 1993, págs. 235-244.) 


\section{LOS USOS DEL IMPERFECTO DE SUBJUNTIVO}

Se documentaron 232 casos del imperfecto de subjuntivo en el material usado para esta investigación, de los cuales 229 corresponden a la forma en $r a$, y 3 , a la forma en se, según se desprende de los datos presentados en el siguiente cuadro:

\section{CUADRO 1}

Distribución de las formas del imperfecto de subjuntivo

\begin{tabular}{|l|c|}
\hline El imperfecto de subjuntivo & $N / \%$ \\
\hline La forma en $r a$ & $229 / 98,7$ \\
La forma en $s e$ & $3 / 1,3$ \\
\hline Total & $232 / 100 \%$ \\
\hline
\end{tabular}

En lo que se refiere a la incidencia de cantase, nuestros datos no difieren mucho de los que documenta Moreno de Alba para el habla culta mexicana ${ }^{29}$. En su material, de 210 casos, siete (3,3\%) son imperfectos de subjuntivo en se, de los cuales, cuatro corresponden a un mismo hablante. A continuación transcribimos los tres ejemplos con la forma en se detectados en nuestro corpus:

(11) Porque mucho ma... mucho maestro se tiene que ir de la docencia precisamente porque no le alcanza mantener una familia con el sueldo que gana. Y aunque pudiese llevar dos actividades, tal vez una en la noche, en otra cosa, pero ya eso sería para él cansado. [YS: 327] ${ }^{30}$

(12) (...) hay otra cosa que tal vez uno pudiese haber hecho si hubiera completado las carreras. [YS: 332]

(13) En realidad lo que me dijo fue que (...) por más licenciada o doctorada que fuese en Historia ese no era mi lugar. [YS: 118]

La forma cantase aparece, según podemos observar, dos veces en una oración concesiva y una vez en la apódosis de un período condicional. Los verbos detectados en esta forma son poder y ser. Los dos ejemplos con el verbo poder corresponden a una misma hablante, quien pertenece a la tercera generación. En esta hablante, además de los dos casos de cantase, documentamos también 17 casos de cantara (ninguno con el verbo poder, pero uno en una oración concesiva). En todos los casos en los que esta hablante emplea cantara el uso del imperfecto de subjuntivo es obligatorio, es decir, el imperfecto de

${ }^{29}$ José G. Moreno de Alba, Valores de las formas verbales en el español de México, México, Universidad Nacional Autónoma de México, 1985, pág. 148.

${ }^{30}$ Los ejemplos se transcriben tal como aparecen en el material de Solano. Solamente a veces, por razones de economía, se acortan. Las partes omitidas se señalan con puntos suspensivos entre paréntesis: (...). 
subjuntivo no puede alternar con ninguna otra forma verbal. En los dos ejemplos con cantase, en cambio, el imperfecto de subjuntivo puede alternar con el condicional. El caso restante de cantase lo registramos en otra hablante femenina, perteneciente a la segunda generación. También en esta hablante registramos las dos formas del imperfecto de subjuntivo. Aparte del ya mencionado ejemplo con cantase, aparecen tres casos de la forma en $r a$, de los cuales dos corresponden al verbo ser, pero ninguno al mismo tipo de oración. Todos estos datos nos hacen pensar que las dos hablantes no usan cantara y cantase indistintamente. No creemos que el empleo de la forma en se esté ligado a ciertos verbos o cierto tipo de oraciones; sin embargo, es posible afirmar que, por lo menos en la variación idiolectal, la forma en se puede implicar lejanía, vaguedad, hipótesis, mayor grado de duda o menos compromiso por parte del hablante, tal como lo plantea Bolinger, a quien citamos más arriba. Por otro lado, es cierto que la incidencia de cantase es mínima, pero la incidencia de los informantes que emplean las dos formas llega a un $4,76 \%$, que ya no es un porcentaje despreciable ${ }^{31}$.

Todas las formas del imperfecto de subjuntivo documentadas las clasificamos primeramente en dos grupos principales, dependiendo de si se encuentran en oraciones sintácticamente independientes o en oraciones que establecen relaciones de dependencia sintáctica, sea con otra oración o sea con una palabra que forma parte de otra oración.

\section{ORACIONES INDEPENDIENTES (30 CASOS; 12,9\%)}

En el primer grupo recogemos los casos en los que el imperfecto de subjuntivo se emplea en oraciones sintácticamente independientes, esto es, oraciones que no están subordinadas a ninguna otra unidad sintáctica. De esta manera, agrupamos aquí las ocurrencias de este tiempo verbal en oraciones simples, coordinadas y principales (o subordinantes). Incluimos también sus usos lexicalizados.

\subsection{Oraciones simples o coordinadas (6 casos; 2,6\%)}

Se registraron seis casos en los que el imperfecto de subjuntivo se emplea en las oraciones simples o coordinadas. El primer caso que ubicamos dentro de

\footnotetext{
${ }^{31}$ En las entrevistas realizadas por Solano participaron en total 42 informantes, de los cuales, no obstante, cinco son personas que dirigen diferentes charlas o conferencias. Sus intervenciones son realmente mínimas y en tres de ellos no documentamos ni un solo caso del imperfecto de subjuntivo.
} 
este apartado corresponde a una oración precedida por la locución interjectiva Dios guarde:

(14) Uno siempre está en crisis y Dios guarde no estuviéramos siempre... [YS: 178]

En esta oración se expresa una volición, una exhortación en forma de advertencia, y el uso del subjuntivo es obligatorio. Como se trata de una exhortación contrafactual, se utiliza el imperfecto de subjuntivo (compárese: Dios guarde no estemos siempre en crisis (en el futuro); Dios guarde no estuviéramos siempre en crisis (en el presente, en general); Dios guarde no hubiéramos / hubiésemos estado siempre en crisis (en el pasado).

En los cinco casos restantes el imperfecto de subjuntivo puede alternar con el condicional. Se trata de los verbos modales deber (1 caso) y poder (2 casos), y del verbo decir (2 casos indénticos). Ejemplos:

(15) Es técnico y debiera ser en Arquitectura... [YS: 15]

(16) Eso se pudiera hacer en alguna Universidad. [YS: 75]

(17) ¿Cómo te dijera? [YS: 118]

La Real Academia habla del uso indistinto del imperfecto de subjuntivo y del condicional «tratándose de verbos modales en frases de significado potencial» ${ }^{32}$. En nuestra opinión, la posibilidad de utilizar el condicional y el imperfecto de subjuntivo en este tipo de oraciones no supone una alternancia en distribución libre, sino que implica una distinción significativa. El hablante acude a debiera para atenuar la obligación y/o para distanciarse un poco de lo que está afirmando. Y, por el contrario, emplea debería con el fin de acentuar la obligación y/o mostrar su compromiso con lo que está afirmando. De la misma manera emplea el verbo poder: pudiera aparece cuando el hablante no está completamente convencido y/o cuando no quiere comprometerse con lo que está diciendo, en cambio podría implica un mayor grado de convicción y/o de compromiso. En cuanto al verbo decir, se utiliza dijera cuando hay más duda y menos claridad, y en el caso contrario, esto es, cuando hay menos duda y más certeza, diría.

\subsection{Oraciones principales (4 casos; $1,7 \%$ )}

Se documentaron cuatro casos en los que el imperfecto de subjuntivo aparece en la oración principal (o subordinante). En dos casos se trata del verbo parecer que rige una oración sustantiva. Veamos los ejemplos:

\footnotetext{
${ }^{32}$ Real Academia Española, op. cit., pág. 481.
} 
(18) $\mathrm{Y}$ en el Liceo y en esos colegios pareciera que (...) solicitaban ciertos requisitos. [YS: 51]

(19) Y pareciera que esa tarde o parecía que esa tarde no estaban funcionando (...). [YS: 159]

Hermerén registró este uso de pareciera en algunos periódicos hispanoamericanos y desde su punto de vista el imperfecto de subjuntivo se emplea «no como alternativa de la forma del potencial sino más bien del presente de indicativo» ${ }^{33}$. Moellering menciona un caso de pareciera empleado en una oración causal introducida por como, donde, de acuerdo con él, el valor de la forma cantara es más bien de cantaba ${ }^{34}$. En nuestra opinión, pareciera se utiliza como alternativa de parecería, y las dos formas, a su vez, se oponen a $p a-$ rece y parecía, ya que ambas implican hipótesis, duda o incertidumbre. La forma en $r a$ y el condicional, sin embargo, no se usan indistintamente: frente a parecería, pareciera indica un mayor grado de estos valores modales.

En los dos casos restantes el imperfecto de subjuntivo se emplea en la apódosis de un período condicional. En uno de ellos, todo el período se refiere a hechos proyectados hacia el futuro y el verbo de la prótasis está en presente de indicativo. En el otro, todo el período expresa hechos irreales o contrafactuales referidos al pasado, y el verbo de la prótasis está en pluscuamperfecto de subjuntivo. En ambos casos podría usarse el condicional en vez del imperfecto de subjuntivo. Considérese los ejemplos:

(20) Porque si yo logro atraer el interés de ellos hacia este proyecto pudiera ser que en un futuro mu... muy próximo yo pueda desarrollar el proyecto de Áreas de Interés Biológico. [YS: 270]

(21) (...) hay otra cosa que tal vez uno pudiese haber hecho si hubiera completado las carreras. [YS: 332]

Cuando el período condicional indica hechos posibles en el futuro, normalmente se utiliza en la apódosis el futuro de indicativo ( $u$ otra forma con valor de éste). En (20) aparece, no obstante, el imperfecto de subjuntivo, que se emplea, en comparación no solamente con el futuro, sino también con el condicional, para marcar un grado menor de probabilidad. En (21) el imperfecto de subjuntivo reemplaza también al condicional y las dos formas en este caso tampoco significan exactamente lo mismo. El imperfecto de subjuntivo frente al condicional se usa para marcar un mayor grado de duda o de hipótesis ${ }^{35}$.

${ }^{33}$ Ingrid Hermerén, El uso de la forma en ra con valor no-subjuntivo en el español moderno, Lund, Lund University Press, 1992, pág. 75.

${ }^{34}$ Ibíd.

${ }^{35}$ En (21) cantase aparece después del adverbio modal tal vez. En todo el corpus registramos en total 17 casos de oraciones introducidas por los adverbios modales tal vez (13) y quizá(s) (4) en las que podría emplearse el imperfecto de subjuntivo. Los tiempos verbales usados en ellas son el imperfecto de indicativo (6), el pretérito indefinido (5), el condicional (5) y el imperfecto 


\subsection{Usos lexicalizados (20 casos; $8,6 \%)$}

Se agrupan en este apartado las 19 documentaciones del verbo ver en segunda o tercera persona singular del imperfecto de subjuntivo vieras o viera. En ciertas áreas de Hispanoamérica (América Central y México), este uso del verbo ver

ha pasado a generalizarse tanto que ha desaparecido su verdadero valor, (...) sirviendo simplemente para redondear la frase con cierta connotación vaga adverbial o interjeccional, como 'desgraciadamente', 'por raro que parezca', o 'ciertamente', o 'no lo querrás creer, pero...', etc. ${ }^{36}$

Moreno de Alba, en el material recogido para el habla culta mexicana, detectó cuatro casos de viera(s), que equivalían a un $1,9 \%$ de todas las apariencias del imperfecto de subjuntivo ${ }^{37}$. Si comparamos este dato con el nuestro, vemos que su uso en el habla culta costarricense es más frecuente. Veamos algunos ejemplos tomados del corpus que usamos para esta investigación:

(22) ¡Vieras qué bueno estuvo [el seminario]! [YS: 88]

(23) ¡Vieras cuando vienen con todo el chunchero! [YS: 105]

(24) ¡Viera qué tristeza me daba a mí. [YS: 339]

(25) Vieras ahora en... en Semana Santa me fui allá donde mi gente, al pueblo. [YS: 103]

(26) Vieras el susto que me llevé porque ahí pasa la puerta abierta todo el santo día. [YS: 103]

Reunimos todas estas formas en un solo grupo aunque no nos parece que todas hayan perdido su valor original del verbo. Por ejemplo, en (23) se expresa un deseo referido al presente y en otras variantes del español se usaría la misma forma con la preposición si: Si vieras cuando vienen con todo el chunchero. En (24) y (26) se denota un deseo referido al pasado y la forma del imperfecto de subjuntivo parece estar sustituyendo el pluscuamperfecto de subjuntivo: Si hubieras visto qué tristeza me daba a mí; Si hubieras visto el susto que me llevé 38 .

de subjuntivo en se (1). La hablante que emplea cantase, sin embargo, en otra ocasión acude al imperfecto de indicativo. Por eso no pensamos que el uso de esta forma en (21) se deba a la presencia de tal vez. También Murillo en su estudio sobre el uso del presente de indicativo llega a la conclusión de que en las oraciones dubitativas se utilizan en el habla culta costarricense principalmente los tiempos verbales del modo indicativo. (Jorge E. Murillo, op. cit., pág. 37).

${ }^{36}$ Charles Kany, op. cit., pág. 223.

${ }^{37}$ José G. Moreno de Alba, op. cit., 1985, pág. 156.

${ }^{38}$ En (22) y (25), por otro lado, vieras podría reemplazarse por fíjate o mira, pero como estas dos formas también las encontramos en el español costarricense, habría que ver en qué contextos se usa viera(s) y en qué contextos otras formas alternativas. Nos parece que este tema merecería un estudio aparte. 
Incluimos también en este apartado el caso en el que la forma en $r a$ del verbo ser forma parte de una conjunción distributiva:

(27) (...) yo había tenido ya cierta asesoría para transformarlo con algún criterio —ya fuera económico, o botánico o taxonómico— (...). [YS: 267]

\section{ORACIONES DEPENDIENTES (202 CASOS; 87,1\%)}

En el segundo grupo se incluyen todas las apariciones del imperfecto de subjuntivo en oraciones subordinadas (o dependientes), esto es, en oraciones que son un elemento sintáctico de la principal (o subordinante). Nuestra clasificación de las oraciones subordinadas coincide a grandes rasgos con la de la Real Academia Española ${ }^{39}$. Diferimos solamente en el hecho de que mientras la RAE maneja solamente oraciones subordinadas sustantivas en función de sujeto, complemento directo y complemento de un sustantivo o adjetivo, nosotros también hacemos referencia a las de atributo y complemento preposicional.

\subsection{Oraciones subordinadas sustantivas (84 casos; 36,2\%)}

\subsubsection{Oraciones sustantivas en función de sujeto (20 casos; 8,6\%)}

Se encontraron 20 casos en los que el imperfecto de subjuntivo aparece en oraciones sustantivas que desempeñan la función de sujeto. En el primer subgrupo incluimos 10 casos donde la oración sustantiva es sujeto del predicado constituido por el verbo copulativo ser + adjetivo. Todos estos enunciados son juicios de valor que el hablante expresa ante un hecho, y el uso del imperfecto de subjuntivo es obligatorio. La estructura de todos estos períodos oracionales es la misma: ser + adjetivo + oración de sujeto. El verbo copulativo se emplea en imperfecto de indicativo (6), presente de indicativo (2), condicional (1) y en un caso el verbo ser está omitido. Véase los ejemplos:

(28) Y cuando decían no era no y era muy frecuente que mantuvieran esos no en situaciones parecidas. [YS: 130]

(29) Es una lástima que un trabajo así se fuera a perder. [YS: 42]

(30) Es muy bueno que hablaras con Sonia para que te contara toda la película. [YS: 269]

(31) Y tal vez sería útil que nos contara después de don Roberto su relación también con don Joaquín. [YS: 294]

${ }^{39}$ Real Academia Española, op. cit, págs. 514-559. 
En dos ocasiones la oración sustantiva de sujeto viene pospuesta al verbo gustar, que está una vez en imperfecto de indicativo y otra en condicional, como se puede apreciar en los siguientes ejemplos:

(32) A mí me gustaba (...) que los chiquillos tuvieran oportunidad de expresarse. [YS: 324]

(33) Yo lo hago pensando sobre todo en mis hijas que no me gustaría que fueran maltratadas por un hombre. [YS: 176]

En otros dos casos la oración sustantiva es sujeto de un predicado con el verbo poder, que semánticamente equivale a la expresión es posible. Por ejemplo:

(34) Puede ser que la gente ya... fuera buena en ese momento. [YS: 262]

En un caso la oración sustantiva es sujeto de un verbo causativo. Así,

(35) Entonces hablé con él y fue cuando se obtuvo la venida del profesor $\mathrm{H}$. a Costa Rica y que él pues... no le costara prácticamente un centavo a la... a la Universidad de Costa Rica. [YS: 184]

En los dos casos siguientes la oración sustantiva es sujeto de una oración atributiva. En ambos el uso del imperfecto de subjuntivo es también obligatorio. En el primero se expresa una hipótesis referida al pasado, mientras que en el segundo, un hecho contrafactual referido al presente. Considérense los ejemplos:

(36) Porque para ella era una falta de respeto que un niño le contestara siquiera sus... a sus mayores. [YS: 107]

(37) Entonces ahora hay güevasales de médicos que entran a Medicina y salieron de Medicina, que supieran Medicina es otra cosa. [YS: 234]

El último subgrupo comprende tres casos de cantara en oraciones sustantivas de sujeto encabezadas por las construcciones el hecho de que (dos casos) y ese que (un caso). El uso del subjuntivo después de estas construcciones es muy frecuente. Por eso a menudo se afirma que exigen subjuntivo, aunque la variación modal es posible ${ }^{40}$. Esto lo demuestran dos casos registrados en nuestro corpus que emplean indicativo, pero que también admiten el imperfecto de subjuntivo. Por ejemplo:

(38) Es muy divertido, casi divertido, el hecho de que en Costa Rica se estrenó la electricidad, por obra de don Manuel Dengo, un día antes que en Nueva York. [YS: 276]

En cuanto a la selección modal en estas oraciones, Sastre Ruano señala que el verbo va en subjuntivo cuando se hace referencia a un hecho conocido y el

${ }^{40}$ Julio Borrego, José J. Gómez Asencio y Emilio Prieto, El subjuntivo. Valores y usos, Madrid, SGEL, 1995, pág. 107. 
hablante expresa una reacción subjetiva, emocional ante este hecho, o cuando se habla de algo cuya realización se presenta como eventual o puramente hipotética ${ }^{41}$. Por otro lado, el subjuntivo puede también emplearse en este tipo de oraciones cuando éstas contienen un bajo valor informativo, o cuando el hablante presupone que su interlocutor tiene conocimiento de la información que se presenta en ellas. Así,

(39) Efectivamente, desde que era estudiante me llamó la atención, como vos también lo decís, el hecho de que siendo, por ejemplo, don Tomás Guardia un dictador aboliera la pena de muerte. [YS: 306]

(40) Pero esa mística, ese... ese conversar directo, ese que J.B. me dijera a mí... [YS: 199]

Hay estudios que apuntan que en la selección modal en este tipo de oraciones influye también la posición de la subordinada: si ésta precede a la principal, que, en realidad, es el predicado, se emplea subjuntivo. En los tres casos encontrados, en uno la subordinada precede al predicado, en otro está pospuesta y en el tercero aparece con el predicado eludido. En los dos casos con indicativo la oración de sujeto está pospuesta. Sin embargo, son muy pocos ejemplos para que podamos sacar alguna conclusión al respecto.

\subsubsection{Oraciones sustantivas en función de atributo (3 casos; $1,3 \%$ )}

Se registraron tres casos en los que la forma cantara es núcleo del predicado de una oración sustantiva que desempeña la función de atributo. Estas oraciones a través del verbo copulativo ser hacen referencia al sujeto de la oración principal. Cuando éste está constituido por un sustantivo que significa finalidad, se emplea el subjuntivo en la oración subordinada, tal como lo demuestra el ejemplo que sigue:

(41) (...) pues la persona que irrespetó cumplió con su objetivo que era que también uno lo irrespetara y por esa vía perdiera la valoración de uno consigo mismo. [YS: 157]

2.1.3. Oraciones sustantivas en función de complemento directo (37 casos; $16 \%)$

Se documentaron 37 casos en los que el imperfecto de subjuntivo se emplea en oraciones sustantivas que funcionan como complemento directo. En el primer subgrupo recogemos siete casos en los que la oración sustantiva depende de un verbo que expresa deseo. Así,

${ }^{41}$ María Ángeles Sastre Ruano, op. cit., págs. 107-111. 
(42) Y antes no querían que las mujeres estudiaran, verdad. [YS: 343]

(43) Yo me recuerdo más de una vez haberme metido yo a mi cuarto a desear... que se murieran. [YS: 129]

Luego tenemos un subgrupo de 11 casos de oraciones sustantivas regidas por verbos que indican ruego, permiso, consejo o mandato. Por ejemplo,

(44) Sí... al... a los nueve meses pedí que me trajeran a San José (...). [YS: 164]

(45) Y que me recomendaba que siguiera ahí que no me sacara de primer grado (...). [YS: 259]

(46) Les exigí que lo fotocopiaran (...). [YS: 139]

En el siguiente subgrupo incluimos ocho casos de oraciones sustantivas regidas por un verbo causativo. Así,

(47) (...) a través del Instituto de Cooperación Iberoamericana hice que ellos me dieran una beca. [YS: 210]

(48) Yo (...) sabía que podía prevenir la inundación o el que la fuerza del agua se llevara toda esta estructura. [YS: 162]

(49) Le iba a dar energía para facilitar que se instalaran acá. [YS: 239]

Otras ocho oraciones sustantivas funcionan como complemento directo del verbo decir. En siete ocasiones el verbo decir funciona como verbo de influencia e indica una orden más o menos atenuada (o un consejo, o un ruego). Ejemplos:

(50) Y entonces mi mamá me dijo aquí en... en una calle aquí cercana, de San José, que cruzara una calle. [YS: 11]

(51) Yo diría más bien que lo redujéramos o restringiéramos a uno de ellos. [YS: 169]

(52) Entonces yo dije que (...) me dieran un chancecito para respirar (...). [YS: 171]

En el caso restante de este subgrupo el verbo decir está modificado por la negación y funciona como verbo de información:

(53) Yo no digo que todos fueran excelentes. [YS: 261]

Creemos que se trata de un rechazo contextual, esto es, una negación de lo que «se ha sugerido o está de alguna forma en el contexto que alguien se ha manifestado en determinado sentido» ${ }^{42}$. El hablante utiliza esta réplica para subrayar que no es precisamente esto lo que pretendía, y para prevenir que el interlocutor piense que se identifica con ello. En este contexto puede aparecer tanto indicativo como subjuntivo, aunque el subjuntivo es, siempre según Bo-

\footnotetext{
${ }^{42}$ Julio Borrego et al., op. cit., págs. 92-94.
} 
rrego et al., el modo más frecuente, dado el no compromiso del hablante con la veracidad del contenido de la oración subordinada (sobre todo en primera persona). El indicativo, pues, se emplea cuando el hablante tiene la certeza de que su idea es verdadera. Nosotros encontramos, además del ejemplo en subjuntivo, otros dos que usan indicativo, de los cuales transcribimos uno para ejemplificar la variación modal en este tipo de oraciones:

(54) Pero usted ve que los... el Club Unión... diay, lo queman. Bueno yo no estoy diciendo que lo quemaron. Pero se queman así. [YS: 68]

Por último, ponemos tres casos de oraciones sustantivas en función de complemento directo dependientes de un verbo de duda:

(55) Entonces por eso un poco cuestionaba que... que se hicieran análisis literarios, que se le dedicara a la... a la... fonética y todo eso, (...). [YS: 97]

(56) No y de hecho no dudo que existiera el cincuenta por ciento real. [YS: 198]

Se emplea el subjuntivo en las oraciones sustantivas cuando éstas están regidas por los verbos de duda en forma afirmativa. No obstante, cuando van precedidos por negación, puede alternar el uso del indicativo y subjuntivo. Porto Dapena aclara que

con subjuntivo el hablante se coloca en el pasado y expresa desde él su duda o desconocimiento, con independencia de las comprobaciones que haya podido realizar después, mientras que con indicativo se sitúa en el presente, desde el cual expresa una duda, duda que no subsiste en el presente, de donde que lo expresado en la oración subordinada se dé como un hecho corroborado y se constate como tal ${ }^{43}$.

2.1.4. Oraciones sustantivas en función de complemento preposicional (10 casos; $4,3 \%$ )

Se encontraron diez oraciones sustantivas que desempeñan la función de complemento preposicional, es decir, que complementan al verbo a través de una preposición exigida por éste. Entre los verbos empleados, igual que en el apartado anterior, hay verbos de influencia (obligación) o voluntad (deseo), así como verbos causativos, tal como se puede apreciar en los siguientes ejemplos:

(57) Entonces ya eso obligaría a que cada encomendero tuviera cincuenta indios. [YS: 289]

${ }^{43}$ José Álvaro Porto Dapena, Del indicativo al subjuntivo. Valores y usos de los modos del verbo, Madrid, Arco/Libros, 1991, págs. 137-138. 
(58) El mismo director se oponía en esas oportunidades a que yo ingresara a la Universidad. [YS: 317]

(59) No teóricamente sino tratando que los muchachos usaran anteojos cuando los necesitaban, se hicieran ver del médico cuando lo necesitaban. [YS: 292]

En dos ocasiones la oración sustantiva de complemento preposicional depende de un verbo de percepción (o actividad mental) modificado por una negación:

(60) (...) yo no me acuerdo en mi vida de que mi papá ni mi mamá se sentaran a trabajar conmigo a hacer una tarea. [YS: 126]

(61) Sí, nunca me había enterado yo que existiera un farmacéutico. [YS: 143$]^{44}$

Cuando estos verbos no se niegan, entonces en la oración subordinada se usa el indicativo. Cuando van en forma negativa, el indicativo y el subjuntivo pueden alternar. Con el subjuntivo, de acuerdo con Borrego et al. ${ }^{45}$, el hablante no se compromete sobre el valor de verdad de la subordinada, bien porque no sabe si es cierta o no, bien porque su interlocutor ya lo sabe, o bien porque no considera necesario manifestarlo. El verbo principal en tal caso se emplea como verbo de duda.

2.1.5. Oraciones sustantivas en función de complemento de un sustantivo o adjetivo (14 casos; $6 \%$ )

Se detectó el imperfecto de subjuntivo en 14 oraciones sustantivas que complementan un sustantivo (12 casos) o un adjetivo (2 casos). El sustantivo, o el adjetivo, funciona en estos casos como núcleo y si significa influencia, voluntad, sentimiento, incertidumbre, finalidad, o si forma parte de un juicio de valor, se emplea el subjuntivo en la oración subordinada, según se puede observar en los ejemplos que presentamos a continuación:

(62) (...) de vez en cuando me daban permiso de que fuera a jugar con las chiquillas y... los chiquillos. [YS: 104]

(63) Y no hubo necesidad de que me viera el médico. [YS: 171]

(64) Vos sabés, la iniciativa de Mayra de que se hiciera ahí un sendero. [YS: 42]

(65) Y esta gente se sentía incómoda, y yo también, de que una persona no universitaria, sin ningún título académico —-mejor dicho- estuviera dándole órdenes. [YS: 317]

${ }^{44}$ En (59) y (61) podemos observar la omisión de la preposición de, que los verbos enterarse y tratar normalmente rigen.

${ }^{45}$ Julio Borrego et al., op. cit., págs. 86-87. 
En un caso el uso del subjuntivo en este tipo de oraciones no está determinado por el carácter semántico del sustantivo al que se refiere, sino por el hecho de que la oración sustantiva indica una acción futura vista desde un punto de referencia pasado:

(66) Entonces tenía la posibilidad de irme con licencia sabática porque estaba a un año y medio de que me la dieran. [YS: 210]

\subsection{Oraciones subordinadas adjetivas (30 casos; 12,9\%)}

Se registraron 30 casos en los que el imperfecto de subjuntivo se emplea en una oración subordinada adjetiva.

Se utiliza el subjuntivo en las oraciones adjetivas cuando éstas se refieren a un antecedente inespecífico, inexistente o desconocido ${ }^{46}$. La inespecifidad del antecedente a su vez viene determinada por el contexto semántico y/o sintáctico ${ }^{47}$. Veamos los siguientes ejemplos tomados de nuestro corpus:

(67) El jefe estaba con la necesidad de que llegara un ingeniero (...) que tuviera un poco de criterio en sus estudios, con mejores condiciones. [YS: 243]

(68) Ahora, todo esto se puede complementar con un decreto que se dio en setiembre (...) de mil ochocientos treinta y tres en que se dijo que toda aquella persona que tuviera mal de lázaro o lepra sería pasada... y $h u$ yera del Lazareto, se le aplicaría la pena de muerte. [YS: 311]

(69) Bueno, la parte de parque, esa se iba a desarrollar sobre todo para atraer turismo científico, digamos, con ciertas especies que tuvieran alguna... alguna significancia (...). [YS: 267]

(70) Y ya había hecho contacto con gente en los Estados Unidos y yo había tenido ya cierta asesoría para transformarlo (...) en algo de atractivo turístico, digamos, que viniera... [YS: 267]

(71) (...) cuando veía un chiquillo que era un chiquillo lerdo en el trabajo entonces investigaba qué era el asunto; si le costaba mucho, que si tenía quién le ayudara; (...). [YS: 325]

Según observamos, los elementos que hacen que el antecedente se perciba como inespecífico pueden ser diferentes: el grado de determinación del antecedente (el artículo un) y/o una palabra de valor volitivo que forma parte del predicado de la oración principal (el sustantivo necesidad), como en (67); una forma verbal que localiza la acción de la oración en el ámbito de la posterioridad, sea con referencia al momento del habla, o sea con respecto a un punto de referencia pasado, como el condicional en (68), o una forma verbal con valor modal que la sitúa en el ámbito de lo eventual o potencial, como la perífrasis ir

${ }^{46}$ José Álvaro Porto Dapena, op. cit., 1991, pág. 160.

${ }^{47}$ Jorge E. Murillo, op. cit., pág. 115. 
$a+$ infinitivo en (69); la presencia de la preposición final para, que siempre introduce una oración orientada hacia el futuro, como en (70); la oración interrogativa que le asigna un carácter dubitativo a la oración, como en (71).

El uso del subjuntivo es también obligatorio en las oraciones adjetivas cuando éstas se refieren a un antecedente cuya existencia se niega ${ }^{48}$. En nuestro corpus se encontraron cuatro casos de la forma cantara usada en este contexto, de los cuales transcribimos tres:

(72) No hay un... un... una... una forma para educar a los hijos que pudiera por lo menos servir de base, de fundamento, (...). [YS: 169]

(73) (...) en el segundo semestre de ese segundo año ya no estudié más Medicina, ni nada que tuviera que ver con eso, (...). [YS: 77]

(74) Pero difícilmente hubo otro que pudiera recuperar [la inversión]... [YS: 288]

En (72) la negación se establece por medio del adverbio de negación no y se extiende también al antecedente. La construcción no hay una forma equivale en tal caso a no hay ninguna forma. En (73), por el contrario, ya el mismo antecedente está constituido por un cuantificador negativo, el pronombre indefinido nada. En (74) podemos observar que ciertas expresiones pueden también implicar la negación del antecedente y hacer que el verbo de la adjetiva vaya en subjuntivo.

En (72), además, vemos que se usa el imperfecto de subjuntivo en la subordinada adjetiva a pesar de que la acción que denota la principal es coexistente con el acto del habla. Desde nuestro punto de vista el hablante prefiere esta forma a la del presente de subjuntivo para subrayar mayor grado de incertidumbre y de inespecificidad del antecedente. Algo parecido ocurre en el ejemplo que sigue:

(75) Y entonces claro, como a veces no se puede, no se acostumbran a que uno todavía tiene que dedicarle su tiempo... conflicto cuando uno no... no... no puede disponer de todo el tiempo que ellos quisieran, ¿verdad? [YS: 320]

En dos casos la presencia de cierto tipo de adverbios requiere el uso del subjuntivo. Considérese los ejemplos:

(76) Incluso yo hablé con Luis Fernando y él me apoyó en un permiso que me... que me tuvieran que dar eventualmente para una beca con el AID. [YS: 54]

(77) Ahora, la pena de muerte en las constituciones se habló de que se aplicaba por homicidio, por atentar contra el orden público que posiblemente pusiera en peligro la seguridad del Estado. [YS: 310]

${ }^{48}$ José Álvaro Porto Dapena, op. cit., 1991, pág. 161. 
Si en (76) quitamos el adverbio eventualmente y en (77) el adverbio posiblemente, cambia el sentido de la oración, los hechos designados por la oración pierden el rasgo de eventualidad o posibilidad y el uso del indicativo se hace posible: él me apoyó en un permiso que me tenían (tuvieron) que dar; la pena de muerte se aplicaba por atentar contra el orden público que ponía en peligro la seguridad del Estado.

En un caso el antecedente está formado por un superlativo. La oración adjetiva denota una acción futura vista desde un punto pasado, por eso encontramos en ella la forma del imperfecto de subjuntivo:

(78) Entonces el más fuerte del grupo (...) tenía que tirar el tarro lo más largo que pudiera. [YS: 248]

En otros dos casos documentados el hablante, a pesar de referirse a hechos pasados y reales, emplea subjuntivo. Véase los ejemplos:

(79) Para eso primero se hacía un levantamiento topográfico donde se incluían los árboles que tuvieran un diámetro de diez o superior a diez centímetros. [YS: 37]

(80) Porque yo no tenía asesor. Yo no tenía aquí... yo no tenía allá. Yo podía hacer lo que yo quisiera. [YS: 215]

En los dos ejemplos que acabamos de aducir, se podría utilizar también el indicativo: se incluían los árboles que tenían un diámetro de diez centímetros; yo podía hacer lo que yo quería. Resulta difícil delimitar los factores que determinan el empleo de uno u otro modo en estos contextos. Es posible que el hablante use el subjuntivo porque presenta los hechos no respecto al acto del habla, sino respecto al momento pasado en el que estos hechos todavía no tenían ningún referente concreto. Sin embargo, cabe también la explicación de que se emplea el subjuntivo porque el hablante en el momento de la enunciación no tiene en la mente ningún antecedente concreto, específico, o porque simplemente quiere presentarlo así, que es lo que ocurre en los siguientes dos ejemplos:

(81) Yo la ayudaba en las materias mías y siempre andaba protegiéndola y dándole y... y... salvándole más de un problemita que ella tuviera, (...). [YS: 326]

(82) (...) había que ir muy bien preparado porque nos vigilaba la profesora, nos vigilaba el maestro o la maestra que tuviera el grupo, así es que... [YS: 337]

En el último subgrupo recogemos tres casos de oraciones adjetivas en subjuntivo que están construidas con los verbos modales deber o poder, de los cuales transcribimos dos:

(83) (...) en ninguna de todas [las escuelas] conozco yo que haya una aularecurso, que es la verdadera aula que debiera existir con mayor frecuencia. [YS: 126] 
(84) Hay muchas cosas que pudieran ser no comprendidas por la juventud actual (...). [YS: 168]

Aunque en (83) el antecedente tiene carácter referencial o específico y en (84) se ve afectado por el cuantificador muchas, que hace que el antecedente se sienta prácticamente existencial, el modo empleado en las oraciones subordinadas es subjuntivo. Se podría pensar que el imperfecto de subjuntivo se emplea en estos casos con valor del condicional, pero nos parece que el significado de estos dos tiempos no es idéntico. Creemos que, al igual que en las oraciones simples, los hablantes acuden a la forma cantara para mostrar menos compromiso con la veracidad de lo que se indica en la oración subordinada y/o para atenuar la obligación, en el caso del verbo deber, y/o para indicar mayor grado de hipótesis, en el caso del verbo poder.

\subsection{Oraciones subordinadas circunstanciales (88 casos; 38\%)}

\subsubsection{Oraciones temporales (12 casos; 5,2\%)}

Se encontraron 12 casos en los que el tiempo verbal que nos interesa en este estudio aparece en una oración temporal. La mayoría de ellos, siete, se detectó en oraciones encabezadas por la locución antes de que. Veamos, por lo menos, tres:

(85) En primer término cuáles fueron los casos de pena de muerte aplicados antes de que se suprimiera esa pena (...). [YS: 306]

(86) (..) antes de que se... que se realizara la revolución rusa en América se había realizado una revolución que había enteramente convertido un país en un país nuevo en estructura social y política. [YS: 304]

(87) $\mathrm{Y}$ bueno... pero antes de... de... —digamos— de que se diera eso, yo pensaba trabajar con niños (...). [YS: 27]

El hecho que se describe en las oraciones temporales introducidas por antes de que es siempre posterior al que se menciona en la oración principal. Por eso estas oraciones se construyen siempre con subjuntivo. El imperfecto de subjuntivo se emplea cuando se hace referencia a acciones pasadas ocurridas antes de otras también pasadas, que, como se desprende de nuestros ejemplos, pueden expresarse en diferentes tiempos pretéritos de indicativo.

En un caso, que presentamos a continuación, la oración temporal está introducida por después de que. Se usa la forma cantara en este ejemplo porque el verbo se refiere a una acción futura y la referencia se hace desde un punto pasado:

(88) Y que me recomendaba que siguiera ahí que no me sacara de primer grado aunque lo perdiera. Que no me sacara pero que después de que... que... de que me pusiera en otra escuela para evitar algún problema. [YS: 259] 
En cuanto al uso del modo verbal en las oraciones temporales introducidas por después (de) que, se emplea el subjuntivo cuando se denota una acción en el futuro, sea con respecto al momento de la enunciación, sea con respecto a un punto anterior a él. Por otro lado, se utiliza el indicativo cuando se expresa una acción pasada anterior a la de la oración principal. Sin embargo, según afirman algunos autores ${ }^{49}$, en este contexto el indicativo puede alternar con el subjuntivo, que se emplea, ya por analogía que se establece entre la locución después (de) que y antes (de) que, ya por razones discursivas o de estilo. Nosotros encontramos siete oraciones temporales encabezadas por después de que que hacen referencia a acciones pasadas, pero en ninguna de ellas aparece el imperfecto de subjuntivo. Véase los ejemplos que siguen:

(89) Bueno, después de que presentamos la... la... tesis tuvimos algunas reuniones con alguna gente de La Caja, verdad. [YS: 31]

(90) Después de que me egresé me vine inmediatamente a trabajar corrientemente. [YS: 262]

En otros tres casos el imperfecto de subjuntivo aparece en oraciones temporales introducidas por la locución hasta que, después de la cual se emplea este tiempo verbal cuando la oración expresa un límite en el futuro visto desde un punto anterior al momento de la enunciación. Ejemplos:

(91) Ese año yo tuve que empezar a trabajar porque era mi materia pri... mi materia madre, no podía llevar nada más hasta que ganara esa. [YS: 199]

(92) Y luego el cadáver no se sepultaba inmediatamente en el caso de un traidor porque... la... hasta que el sol se ocultara se le entregaría a la familia. [YS: 311]

En el segundo ejemplo, no obstante, parece que en el uso de la forma cantara influye también otro factor. El hablante cuenta cómo se aplicaba la pena de muerte, es decir, describe una serie de acciones pasadas habituales y por eso podría haber usado el imperfecto de indicativo en toda la secuencia: el traidor era acompañado por dos sacerdotes, en el transcurso de camino nadie debía pronunciar palabra, el cadáver no se sepultaba inmediatamente porque hasta que se ocultaba el sol se le entregaba a la familia. Pensamos, junto con Murillo ${ }^{50}$, que el hablante emplea el indicativo donde tiene la certeza de que lo que afirma es verdadero. En el caso contrario, que es el nuestro, opta por el subjuntivo.

${ }^{49}$ María Ángeles Sastre Ruano, op. cit., págs. 160-161. Manuel Pérez Saldanya, «El modo en las oraciones subordinadas relativas y adverbiales», Gramática descriptiva de la lengua española, Ignacio Bosque y Violeta Demonte, dirs., Madrid, Espasa, 1999, págs. 3253-3322.

${ }^{50}$ Jorge E. Murillo, op. cit., pág. 147. 
Se registró un caso en el que el imperfecto de subjuntivo aparece en una oración temporal introducida por mientras. Borrego et al. apuntan que después de este nexo el verbo va en subjuntivo cuando la oración expresa un hecho cuya persistencia es una condición para la persistencia de lo que se dice en la oración principal ${ }^{51}$. En tal caso existe una relación causa-efecto entre la oración principal y la temporal, que, de esta manera, adquiere un carácter condicional, según se puede apreciar en el ejemplo tomado de nuestro corpus:

(93) Mientras ella no informara nada no podían mandar otro profesor. [YS: 51]

Podemos observar cómo en (93) se afirma que la causa de que no podían mandar otro profesor era el hecho de que ella no informaba nada. La oración se podría parafrasear de esta manera: Si ella hubiera (hubiese) informado algo, habrian (hubieran, hubiesen) podido mandar otro profesor.

\subsubsection{Oraciones modales (12 casos; $5,2 \%)$}

Se documentaron 12 casos en los que el imperfecto de subjuntivo se emplea en una oración modal. Tres de estas oraciones están introducidas por el adverbio de modo como y son idénticas. Transcribimos una de ellas:

(94) Y hora y media en la tarde lloviera o tronara, como fuera, a pie. [YS: 267]

Las oraciones modales se refieren a la manera como se realiza la acción expresada por el verbo de la oración principal. Cuando el modo de realizarla es inespecífico, inconcreto, desconocido o no experimentado por parte del hablante, se utiliza el subjuntivo. Se emplea el imperfecto de subjuntivo cuando se hace referencia al modo de realizar una acción pasada. En nuestro ejemplo, no obstante, la oración se utiliza más bien como hueco semántico, que puede ser sustituido por cualquier enunciado que cuadre con el contexto dado. La oración también podría remplazarse por la locución de cualquier manera (modo).

En otros siete casos la forma cantara aparece en oraciones modales encabezadas por el adverbio como seguido de la conjunción si, formando así la locución como si, que, gracias a la presencia de si, le otorga a la oración un valor condicional-modal. De los siete ejemplos documentados con como si transcribimos tres:

(95) Es decir, hay personas menores que se... se... se dirigen a uno como si uno fuera un... uno igual. [YS: 250]

${ }^{51}$ Julio Borrego et al., op. cit., págs. 142-143. 
(96) Eso fue en el año dieciseis. Heredia se sentía como si fuera la capital de Costa Rica. [YS: 297]

(97) Es que siempre dicen: ¡Pobrecita! ¡Pobrecita! Pero en realidad es como si se le cortara a uno la vida. [YS: 321]

Como si en (95) y (96) introduce oraciones de carácter falso o contrafactual orientadas hacia el momento de la enunciación (como si uno fuera uno igual = «uno no es uno igual») o hacia un punto anterior al momento de la enunciación (como si Heredia fuera la capital de Costa Rica $=$ «Heredia no era la capital de Costa Rica»). El segundo ejemplo demuestra que el imperfecto de subjuntivo no sirve en este contexto solamente para referirse a hechos presentes o futuros, según afirman Borrego et al. ${ }^{52}$, sino también para designar hechos pasados simultáneos a otros pasados. En (97) la oración con como si tiene más bien valor hipotético.

En un caso la oración modal está introducida por la locución como que, la cual se usa, sobre todo en el español americano, con el valor de como $s i^{53}$. En nuestro ejemplo, que presentamos a continuación, la oración con como que tiene valor hipotético referido al presente:

(98) Es que sí, todo lo que es... es como por ejemplo que trabajara en un colegio nocturno... privado... entonces lo puede hacer perfectamente. [YS: 331]

En el último caso al adverbio como se le une la locución para que. La oración, de esta manera, adquiere un valor final-modal y el uso del imperfecto de subjuntivo en ella se obedece a las mismas reglas que rigen su uso en las oraciones finales: cuando el contenido de esta oración está orientado hacia el futuro visto desde un momento pasado, la forma empleada en ella es el imperfecto de subjuntivo. Así,

(99) Y yo nunca lo [su nombre] oí mencionar tampoco así como para que me interesara conocerlo no, ¿verdad? [YS: 257]

\subsubsection{Oraciones finales ( 24 casos; $10,4 \%)$}

Se detectaron 24 oraciones finales en las que aparece el imperfecto de subjuntivo. 19 de ellas están introducidas por la locución para que, cuatro por la conjunción que y una por la conjunción porque. Ejemplos:

(100) (...) yo tenía un tío que les... estaba preparando los del sexto grado mío para que fueran al colegio. [YS: 343]

\footnotetext{
52 J. Borrego et al., op. cit., pág. 66.

${ }^{53}$ Estrella Montolío, «Las construcciones condicionales», Gramática descriptiva de la lengua española, op. cit., págs. 3643-3738.
} 
(101) Pero ya como se acerca mi pensión el año pasado le mandé una carta al Director que me diera tiempo completo este año y punto. [YS: 132]

(102) (...) y ante esas cosas uno no puede tampoco presionarse porque también se puede morir de esa presión o tensión que ejerce sobre uno cuando algo no sale como uno deseó, a pesar de que se hizo todo el esfuerzo porque así fuera. [YS: 171]

En todos los casos documentados el sujeto del verbo principal es diferente del sujeto del verbo subordinado. En seis ejemplos, no obstante, encontramos que el sujeto de la oración final es correferencial con un elemento de la oración principal, ya sea el complemento directo, indirecto u otro. Por ejemplo:

(103) Pero me formaron para que yo entendiera que no aprendí cosas (...). [YS: 204]

(104) Me invitaron para que contara a los niños cómo habíamos hecho para conseguir la clínica y todas esas cosas. [YS: 336]

En dos ocasiones la oración final no expresa la finalidad de la oración principal, por lo tanto, cabría hablar de oraciones pseudofinales, que desde el punto de vista formal (el nexo para que) se pueden considerar finales, pero no semánticamente, ya que carecen del rasgo de intencionalidad o de propósito. Además, el nexo en este caso no es permutable por locuciones como a fin de que, con el fin (propósito) de que ${ }^{54}$. Véase estos ejemplos:

(105) Yo la ayudaba en las materias mías y siempre andaba protegiéndola y dándole y... y... salvándole más de un problemita que ella tuviera, para que se fuera a quedar en Educación Física... [YS: 326]

(106) No las supera todas pero bueno, por lo menos se le jaló el aire y [el que se recapacitara en un montón de cosas] era la condición para que él volviera a comprar [la farmacia], verdad. [YS: 14]

En (105) se expresa, en forma de contraste con la oración principal, un objetivo no deseado, que, por ciertas razones, sobrevenía, mientras que en (106) más bien se describen circunstancias o medios que condicionan el cumplimiento del objetivo ${ }^{55}$. En este ejemplo, además, observamos que la oración final no complementa a la oración principal en su totalidad, sino que establece la relación de dependencia solamente con un elemento de ésta: con el sustantivo condición.

En la mayoría de casos de este tipo de oraciones, y tal como se aprecia en todos los ejemplos hasta aquí aducidos, el imperfecto de subjuntivo depende de un verbo en pretérito perfecto simple o imperfecto de indicativo. En nuestro

${ }^{54}$ José Álvaro Porto Dapena, op. cit., 1991, pág. 210. Carmen Galán Rodríguez, «La subordinación causal y final», Gramática descriptiva de la lengua española, op. cit., págs. 3597-3642.

${ }^{55}$ Ibíd. 
corpus detectamos solamente tres ejemplos en los que está regido por un verbo en una forma diferente: un caso con el presente de indicativo, otro con el condicional y el tercero con el imperfecto de subjuntivo:

(107) Yo saco el rato de ir al almacén general para que vieras los productos que hay ahí. [YS: 149]

(108) Podría hacerlo para que recordáramos tantos buenos tiempos que pasamos en Heredia, gracias a la Escuela Normal. [YS: 296]

(109) Es muy bueno que hablaras con Sonia para que te contara toda la película. [YS: 269]

Estos son también los tres únicos casos en los que la forma cantara hace referencia al futuro y no al pasado. El ejemplo (107), por otro lado, lo consideramos anómalo, pues no es común, y la gramática normativa tampoco menciona que el imperfecto de subjuntivo pueda depender del verbo principal en presente de indicativo (en realidad, la hablante debería haber usado el presente de subjuntivo).

\subsubsection{Oraciones causales ( 5 casos; $2,2 \%$ )}

Se registraron cinco oraciones causales en las que se emplea la forma verbal que es objeto de nuestro estudio. Tres de estas oraciones están introducidas por no porque y en ellas se niega la validez de la causa. Estas oraciones se correlacionan al mismo tiempo con otras encabezadas por sino porque, donde se expresa la causa considerada como válida. Por ejemplo:

(110) No porque ella no quisiera sino porque la mamá le exigía quedarse en la casa cuidando unos hermanitos, mientras ella iba a trabajar, (...). [YS: 325]

En el cuarto caso, no obstante, ya no encontramos esta estructura correlativa. La oración está introducida por el nexo porque y se subordina a una oración que contiene el adverbio negativo nunca:

(111) No, nunca me sentí acomplejado porque ellos se sintieran incómodos o me rebatían algún punto que al final de cuentas, con la práctica, la experiencia que yo tenía... [YS: 317]

En realidad, en el ejemplo anterior hay dos oraciones causales coordinadas en distinto modo, aunque ambas dependen de la misma oración. Al utilizar el subjuntivo en la primera, el hablante manifiesta la duda en cuanto a la validez de la causa, mientras que al usar el indicativo en la otra, expresa su compromiso con la veracidad del enunciado. 
En el caso restante, la forma cantara también aparece después del nexo porque, pero ya no hay negación en la oración subordinante. En nuestra opinión, aquí tiene valor de pretérito perfecto simple. Véase el ejemplo:

(112) Yo creo que soy solo yo la única persona, de todos mis compañeros, que sabe la historia de por qué nunca nos dieron Física. Por curioso, verdad. (...) Porque me tocara ser compañera mía y todas esas cuestiones, verdad. [YS: 51] ${ }^{56}$

\subsubsection{Oraciones condicionales (27 casos; $11,6 \%$ )}

Se documentaron 27 oraciones condicionales en las que aparece el imperfecto de subjuntivo. Todas están introducidas por el transpositor si, menos una que está encabezada por la conjunción que. Decidimos incluirla en este apartado ya que por su contenido se asemeja a otra con si:

(113) ¿Qué tal si mi mujer y yo fuéramos los dos arquitectos? [YS: 203]

(114) ¡Y qué tal que se trabajara así a la loca y que ¡pru-rru-rrú, tome! [YS: 149]

En 18 casos la oración condicional se orienta hacia el momento del habla y expresa hechos diferentes o contrarios, a los actuales, según se puede apreciar en los ejemplos que siguen:

(115) Si el personal de... de preescolar y de primaria estuviera bien preparado, estuviera bien remunerado, la cosa sería distinta. [YS: 331]

(116) Pero si yo tuviera en la computadora que tenemos arriba una tarjeta emuladora y el modem lo puedo hacer yo directamente. [YS: 62]

(117) Si se conservaran había muchísimos más documentos que aquí en Costa Rica. [YS: 191]

Se dice si el personal estuviera bien preparado, cuando en realidad no lo está; si yo tuviera una tarjeta emuladora, cuando en realidad no la tengo; si los documentos se conservaran, cuando en realidad no se conservan.

En nueve casos la forma cantara se emplea en la prótasis para describir hechos hipotéticos o potenciales, orientados hacia el futuro. Por ejemplo:

(118) Yo pienso que más bonita que ahora, pero si le preguntáramos a un niño de ahora él nos diría que ahora es más bonita que la de antes. [YS: 248]

(119) Entonces, digamos como posibilidad para defenderme algún día si fue$r a$ necesario, yo creo que lo puedo hacer. [YS: 25]

(120) Y él decía — no le faltaba razón — decía que si cualquiera que estuviera trabajando allá y se... ingresara a la Universidad eso le restaba ca-

${ }^{56}$ La oración es un poco confusa a causa del empleo de los pronombres personales. Pensamos que en vez de me debería aparecer le: Porque le tocara ser compañera mía. 
pacidad a la función porque, mejor dicho, le restaba eficiencia (...). [YS: 317]

Al utilizar el imperfecto de subjuntivo, el hablante muestra su vacilación ante la probabilidad de la realización del hecho, esto es, lo considera de cumplimiento improbable. Cuando el hablante considera que aquello va a suceder, cuando lo ve como posible, usa el presente de indicativo ${ }^{57}$. Ésa sería entonces la diferencia entre si le preguntáramos a un niño y si le preguntamos a un niño, si fuera necesario y si es necesario, si se ingresara a la Universidad y si se ingresa a la Universidad. En (120), sin embargo, nos parece que la forma del imperfecto de subjuntivo se emplea por atracción con el verbo, también en imperfecto de subjuntivo, de la oración adjetiva que modifica al sujeto de la oración condicional. En realidad se trata de la oración Si cualquiera que esté trabajando acá se ingresa a la Universidad eso le resta capacidad a la función en el estilo indirecto, por eso el verbo ingresarse en nuestro ejemplo debería emplearse en imperfecto de indicativo.

A veces, no obstante, no es fácil determinar cuál de estos dos contenidos posee la forma del imperfecto de subjuntivo. Veamos este ejemplo:

(121) Si uno tuviera la oportunidad... de... de... de... hacerse un viajecito al exterior y porque tiene dólares... lo que sea, uno lo hace también. [YS: 179]

Al decir si uno tuviera la oportunidad, el hablante puede presentar el hecho como contrafactual, cuando en realidad no tiene la oportunidad, o también como hipotético e improbable. Viendo el contexto en el que aparece esta oración, sin embargo, optamos por la segunda interpretación.

De las 27 oraciones introducidas por si, 14 aparecen con apódosis. Son varias las formas verbales que se pueden emplear en la apódosis con prótasis en imperfecto de subjuntivo. Nosotros detectamos tres combinaciones: a) con el condicional ( 8 casos); b) con el presente de indicativo (4 casos); y c) con el imperfecto de indicativo ( 2 casos). No encontramos ningún caso de la combinación $s i+$ imperfecto de subjuntivo + imperfecto de subjuntivo. Por otra parte, tampoco registramos ejemplos donde el imperfecto de subjuntivo estuviera sustituido en la prótasis por el condicional o por el imperfecto de indicativo ${ }^{58}$.

\subsubsection{Oraciones concesivas (7 casos; $3 \%$ )}

Se encontraron siete oraciones concesivas cuyo verbo principal está en imperfecto de subjuntivo. Cuatro de ellas están introducidas por la conjunción aunque, de las cuales primero presentamos tres:

${ }^{57}$ José Álvaro Porto Dapena, op. cit., 1991, pág. 224.

${ }^{58}$ Estrella Montolío, art. cit., págs. 3668-3670. 
(122) Y que me recomendaba que siguiera ahí que no me sacara de primer grado aunque lo perdiera. [YS: 343]

(123) [No, sería otra vez maestra.] Aunque el salario estuviera bajo. [YS: 332]

(124) Y pues los medios de comunicación, aunque uno no quisiera saber del mundo, al ver la televisión se da uno cuenta... de toda esa crisis de valores. [YS: 178]

En (122) se indica una concesión u objeción posible en el futuro visto desde un punto pasado. Esto significa que el uso de la forma cantara está regulado por las reglas del estilo indirecto. En (123) se hace referencia a un hecho hipotético en el futuro. Como se trata de un hecho de cumplimiento improbable, se usa el imperfecto de subjuntivo. En (114), en cambio, se expresa un hecho irreal, contrafactual, en el presente.

En la última oración con aunque se hace referencia también a un hecho que no se está cumpliendo en el presente, pero a diferencia de (114) se trata de un hecho conocido, real:

(125) Porque mucho ma... mucho maestro se tiene que ir de la docencia precisamente porque no le alcanza mantener una familia con el sueldo que gana. $\mathrm{Y}$ aunque pudiese llevar dos actividades, tal vez una en la noche, en otra cosa, pero ya eso sería para él cansado. [YS: 327]

Porto Dapena afirma que «a veces usamos también subjuntivo para expresar hechos que nos son perfectamente conocidos, pero que por diversas razones nos interesa presentar como puramente hipotéticos» ${ }^{59}$. Pensamos que éste es el caso de (125). La hablante sabe que el maestro puede llevar dos actividades, no obstante, prefiere presentar el hecho como hipotético o como una conjetura $\mathrm{y}$, por lo tanto, emplea el imperfecto de subjuntivo en lugar del condicional: para indicar mayor grado de hipótesis o conjetura $\mathrm{y}$, al mismo tiempo, menor grado de compromiso personal con lo enunciado.

Además, hay dos casos en los que se emplean estructuras reduplicativas: una que consiste en dos formas verbales idénticas y enlazadas por el adverbio relativo como, y otra en la que las dos formas verbales son distintas y se relacionan por medio de la conjunción disyuntiva $o$. Como las oraciones se refieren al pasado, se emplea el imperfecto de subjuntivo:

(126) El chiquillo antes, fuera como fuera, sabía un poco más de lo exterior y ahora no. [YS: 322]

(127) Y hora y media en la tarde lloviera o tronara, como fuera, a pie, verdad. [YS: 343]

${ }^{59}$ José Álvaro Porto Dapena, op. cit., 1991, pág. 233. 
En el caso restante tenemos una oración concesiva encabezada por la construcción por + adjetivo + que. El hablante adopta aquí una actitud polémica ante un hecho que su interlocutor presenta como real (lo sabemos por el contexto) para rebatirlo. Flamenco García habla en este caso del subjuntivo con valor temático y lo diferencia del subjuntivo con valor hipotético ${ }^{60}$. Así,

(128) En realidad lo que me dijo fue que (...) por más licenciada o doctorada que fuese en Historia ese no era mi lugar. [YS: 118]

\subsubsection{Oraciones consecutivas ( 1 caso; $0,4 \%)$}

Se registró un caso en el que la forma cantara aparece en una oración que expresa la consecuencia de lo que se dice en la oración anterior. La oración está introducida por la conjunción que:

(129) Por ejemplo, este domingo anunciaron que no iba a haber luz donde yo vivo, entonces toda la noche del sábado, pasé... pasé soñando: haciendo fogatas, prendiendo fogones y todo este tipo... que dijéramos, que seguro no iba a haber luz. [YS: 252]

En este caso se trata de una oración consecutiva hipotética referida al pasado y la forma cantara corresponde a la forma del condicional perfecto, la cual alterna con la del pluscuamperfecto de subjuntivo: (...) entonces toda la noche del sábado, pasé... pasé soñando: haciendo fogatas, prendiendo fogones y todo este tipo... que habríamos (hubiéramos, hubiésemos) dicho que seguro no iba a haber luz.

\section{RESUMEN DE LOS USOS DEL IMPERFECTO DE SUBJUNTIVO}

En el cuadro que sigue resumimos todos los usos del imperfecto de subjuntivo registrados en el material que usamos para este trabajo. En la primera columna recogemos los usos obligatorios de este tiempo verbal, esto es, los casos en los que no se puede usar ninguna otra forma verbal. En la segunda incluimos los usos no obligatorios, es decir, los casos en los que el imperfecto de subjuntivo puede alternar con otra forma verbal. $\mathrm{Y}$ en la tercera ponemos los usos del imperfecto de subjuntivo en los que se emplea con valor de algún otro tiempo verba:

${ }^{60}$ Luis Flamenco García, «Las construcciones concesivas y adversativas», Gramática descriptiva de la lengua española, op. cit., págs. 3805-3878. 
CUADRO 2.

Resumen de los usos del imperfecto de subjuntivo

\begin{tabular}{|c|c|c|c|c|}
\hline & \begin{tabular}{|c|} 
Uso \\
obligatorio
\end{tabular} & $\mid \begin{array}{c}\text { Uso no } \\
\text { obligatorio }\end{array}$ & $\begin{array}{c}\text { Uso con } \\
\text { valor de } \\
\text { otro tiempo }\end{array}$ & $\begin{array}{c}\text { Total } \\
(N / \%)\end{array}$ \\
\hline 1. Oraciones independientes & & & & $30 / 12,9$ \\
\hline $\begin{array}{l}\text { 1.1. Oraciones simples o coordinadas } \\
\text { 1.2. Oraciones principales } \\
\text { 1.3. Usos lexicalizados }\end{array}$ & $\begin{array}{l}1 \\
- \\
20\end{array}$ & $\begin{array}{l}5 \\
4 \\
-\end{array}$ & $\begin{array}{l}- \\
- \\
-\end{array}$ & $\begin{array}{l}6 / 2,6 \\
4 / 1,7 \\
20 / 8,6\end{array}$ \\
\hline 2. Oraciones dependientes & & & & $202 / 87,1$ \\
\hline $\begin{array}{l}\text { 2.1. Oraciones sustantivas } \\
\text { 2.1.1. de sujeto } \\
\text { 2.1.2. de atributo } \\
\text { 2.1.3. de complemento directo } \\
\text { 2.1.4. de complemento preposicional } \\
\text { 2.1.5. de compl. de sustant. o adjet. } \\
\text { 2.2. Oraciones adjetivas } \\
\text { 2.3. Oraciones circunstanciales } \\
\text { 2.3.1. temporales } \\
\text { 2.3.2. modales } \\
\text { 2.3.3. finales } \\
\text { 2.3.4. causales } \\
\text { 2.3.5. condicionales } \\
\text { 2.3.6. concesivas } \\
\text { 2.3.7. consecutivas }\end{array}$ & $\begin{array}{c}11 \\
12 \\
23 \\
3 \\
18 \\
6 \\
-\end{array}$ & $\begin{array}{l}1 \\
- \\
- \\
1 \\
8 \\
1 \\
-\end{array}$ & $\begin{array}{l}- \\
- \\
1 \\
1 \\
1 \\
- \\
1\end{array}$ & $\begin{array}{c}\mathbf{8 4} / \mathbf{3 6 , 2} \\
20 / 8,6 \\
3 / 1,3 \\
37 \text { / } 16 \\
10 / 4,3 \\
14 \text { / } 6 \\
\mathbf{3 0} / \mathbf{1 2 , 9} \\
\mathbf{8 8} / \mathbf{3 8} \\
12 / 5,2 \\
12 / 5,2 \\
24 / 10,4 \\
5 / 2,2 \\
27 / 11,6 \\
7 / 3 \\
1 / 0,4 \\
\end{array}$ \\
\hline Total $(N / \%)$ & $190 / 81,9$ & $38 / 16,4$ & $4 / 1,7$ & $232 / 100$ \\
\hline
\end{tabular}

\section{PRESENTE DE SUBJUNTIVO POR IMPERFECTO DE SUBJUNTIVO}

En algunas regiones de Hispanoamérica, se emplea frecuentemente un presente de subjuntivo en oraciones subordinadas en casos en que, según las reglas de secuencia temporal, debería usarse un imperfecto de subjuntivo ${ }^{61}$. De acuerdo con estas reglas, el verbo de la oración subordinada debería estar en imperfecto de subjuntivo cuando el verbo principal (o subordinante) está en pretérito simple de indicativo, imperfecto de indicativo, condicional o imperfecto de subjuntivo ${ }^{62}$. La excepción la constituyen casos en que la acción denotada por el verbo de la subordinada se refiere a un momento posterior al acto del habla. El uso del presente de subjuntivo en el español de América, no obstante, va más allá de esta excepción ${ }^{63}$.

${ }^{61}$ Charles Kany, op. cit., pág. 220.

${ }^{62}$ John Butt, Carmen Benjamin, A New Reference Grammar of Modern Spanish, London, Arnold, 1994, pág. 272.

${ }^{63}$ Charles Kany, op. cit., pág. 220. 
En nuestro material registramos 11 casos en los que se emplea el presente de subjuntivo en vez del imperfecto de subjuntivo: siete en oraciones sustantivas (cuatro de sujeto, una de complemento directo y dos de complemento de sustantivo), dos en oraciones adjetivas y dos en oraciones circunstanciales de finalidad. El verbo principal está en seis ocasiones en pretérito indefinido de indicativo, en tres en condicional, en una en imperfecto de indicativo y en una en imperfecto de subjuntivo. En nueve casos documentados la acción denotada por el verbo en presente de subjuntivo se refiere al futuro. Ejemplos:

(130) Porque si yo logro atraer el interés de ellos hacia este proyecto pudiera ser que en un futuro mu... muy próximo yo pueda desarrollar el proyecto (...). [YS: 270]

(131) Que más bien eso se hizo con el fin de que los muchachos le den más importancia al país en cuanto a lo productivo. [YS: 323]

(132) El año pasado la seleccionaron para el Monterrey y la dejaron ahora el tiempo que ella quiera. [YS: 346]

(133) Ya ya... ya nos pasaron... nos pasaron una... una hoja a las ex-alumnas para que firmemos. [YS: 255]

En los dos casos restantes se trata de juicios personales en los que la oración tiene más bien carácter general (o atemporal). Por ejemplo,

(134) Me soñé con... con lo peor que pueda soñarse un individuo que es consentir y ver la maldad en todos sus... en todas sus formas. [YS: 12]

A la vista de los datos obtenidos podemos señalar que el uso del presente de subjuntivo por el imperfecto de subjuntivo no es un fenómeno ajeno al habla culta costarricense, aunque, al mismo tiempo, no está muy extendido. $\mathrm{Su}$ nivel alcanzaría un $4,53 \%$ de la suma de todos los casos del imperfecto de subjuntivo y los del presente de subjuntivo. No registramos ningún caso en el que el hecho denotado por el presente de subjuntivo se refiriera al pasado.

\section{CONCLUSIONES}

La forma en $r a$ es la forma predominante del imperfecto de subjuntivo en el habla culta de Costa Rica. La forma en se no ha desaparecido por completo de esta variante del español moderno, aunque su empleo es mínimo (un 1,3\% del total de todas las apariencias de este tiempo verbal). Cuando se emplea, parece que no funciona como variante libre de cantara, sino que implica, por lo menos en la variación idiolectal, menos compromiso por parte del hablante y/o mayor grado de duda o de hipótesis.

El imperfecto de subjuntivo se emplea en el habla culta costarricense principalmente en contextos donde su uso es obligatorio (un $81,9 \%$ del total de to- 
dos los casos registrados), esto es, en contextos donde el uso de otro tiempo verbal sería inaceptable. Su alternancia con otras formas verbales es posible en un $16,4 \%$ de todos los casos documentados. Esta posibilidad de alternancia se da en las oraciones simples, coordinadas y principales, en las que en un $90 \%$ de casos el imperfecto de subjuntivo puede alternar con el condicional, y en las oraciones adjetivas, en las que un $30 \%$ admitiría otro tiempo verbal, ya sea el condicional, el pretérito perfecto simple de indicativo o el pretérito imperfecto de indicativo. La posibilidad de variación baja en las oraciones circunstanciales, en las que en un $12,5 \%$ de casos el imperfecto de subjuntivo puede alternar con el pretérito imperfecto de indicativo o, en las oraciones condicionales, con el presente de indicativo; lo mismo sucede en las oraciones sustantivas, de las que un $10,7 \%$ admite el uso del pretérito imperfecto de indicativo o del pretérito perfecto simple de indicativo.

Tan solo en un $1,7 \%$ del total de todos los casos documentados el imperfecto de subjuntivo se emplea con valor de otro tiempo verbal. Estos usos se encontraron únicamente en las oraciones circunstanciales, en las que la forma cantara sustituye al condicional perfecto o pluscuamperfecto de subjuntivo (en una consecutiva), al pretérito perfecto simple de indicativo (en una causal), al presente de subjuntivo (en una final) y al pretérito imperfecto de indicativo (en una condicional). No obstante, hay que recordar el carácter confuso de la oración causal, el uso inadecuado del imperfecto de subjuntivo en una oración final cuyo verbo principal está en presente de indicativo y su empleo por atracción con otra forma del imperfecto de subjuntivo en la oración condicional. 